\title{
Conservation and development in conflict: regeneration of wild Davidia involucrata (Nyssaceae) communities weakened by bamboo management in south-central China
}

\author{
Shenhua Qian, Cindy Q. Tang, Sirong Yi, Liang Zhao \\ KUN SONG and YONGCHUAN YANG
}

\begin{abstract}
Protected areas, including nature reserves and management areas, are established for the conservation of biological diversity and protection of the associated natural and cultural resources. These objectives, however, are often in conflict with socio-economic development. We investigated the plant communities dominated by the dove tree Davidia involucrata in a nature reserve on Mount Jinfo, China, where people intensively manage large areas of bamboo stands. We found a significant lack of small-sized main stems of $D$. involucrata (o-25 $\mathrm{cm}$ diameter at breast height; height $>1.3 \mathrm{~m}$ ) and newly emerging sprouts in the reserve. The height-class distribution showed a unimodal pattern, with most individuals (of both D. involucrata and co-occurring species) concentrated in the 16-28 $\mathrm{m}$ height-class, and few individuals in the shrub and sub-canopy layer $\left(1.3^{-8} \mathrm{~m}\right)$. Existing practices to facilitate the spread of bamboo stands, and the need to develop a local market for bamboo shoots received little consideration when the nature reserve was established in 1979 to protect $D$. involucrata. To conserve D. involucrata on Mount Jinfo the appropriate authorities and local parties involved in bamboo harvesting need to focus on methods that are favourable to the life history of this and other tree species, and strategies for their regeneration. These methods will also benefit the conservation of
\end{abstract}

Shenhua Qian (Corresponding author) Postdoctoral Station of Ecology Chongqing University, Chongqing 400045, China

E-mail qian@fastmail.com

CindY Q. TANG Institute of Ecology and Geobotany, Yunnan University, Kunming, China

SIRONG YI Institute of Medicinal Plant Cultivation of Chongqing, Chongqing, China

Liang ZHAO and YongChUAN YANG* (Corresponding author) Faculty of Urban Construction and Environmental Engineering, Chongqing University, Chongqing 400045, China. E-mail ycyang@cqu.edu.cn

Kun Song School of Ecological and Environmental Sciences, East China Normal University, Shanghai, China

*Also at: Key Laboratory of Three Gorges Reservoir Region's Eco-Environment, National Centre for International Research of Low-carbon and Green Buildings, and Joint International Research Laboratory of Green Building and Built Environment, Ministry of Education, Chongqing University, Chongqing, China

Received 17 January 2017. Revision requested 24 February 2017.

Accepted 23 March 2017. First published online 10 July 2017. other highly valued trees that share similar life-history characteristics with $D$. involucrata.

Keywords Bamboo, China, Conservation effectiveness, Davidia involucrata, forest regeneration, Nyssaceae, protected areas, socio-ecological system

\section{Introduction}

D rotected areas, including nature reserves and manage1 ment areas, are established for the effective conservation of biological diversity and protection of the associated natural and cultural resources (DeFries et al., 2007; Dudley \& Stoulton, 2008). These objectives, however, are often in conflict with socio-economic development. Although many proposals have been put forward to simultaneously satisfy human requirements and maintain ecological functions in protected areas (e.g. Daily \& Ellison, 2012), this is not always feasible because of potential conflicts between conservation and socio-economic development (Coggins, 2000; Liu et al., 2007; Ma et al., 2009; Wang et al., 2012).

Human and natural systems are integrated in the sense that people interact with nature (Berkes et al., 2000, 2008; Liu et al., 2007). Local people play important roles in the maintenance of protected areas because of long-standing relationships with these areas (McNeely, 1990; Newmark et al., 1993; Xu et al., 2006), and effective communication and knowledge exchange between various parties are important for management and conservation (Gardner et al., 2009; Davis \& Ruddle, 2010; Raymond et al., 2010). The knowledge held by local communities and people involved in decision making is not usually the explicit and formalized type of knowledge obtained through scientific methods. In China, many protected areas are established and maintained by a strong top-down, command-and-control authority. This limits the opportunities for policy makers, scientists and local participants to cooperate, and hinders knowledge translation and information feedback, possibly leading to unintended results (e.g. Guan et al., 2011; Xu et al., 2012; Zheng \& Cao, 2015).

The subtropical evergreen broad-leaved forests of southcentral China harbour a rich biological diversity (Myers et al., 2000; López-Pujol \& Ren, 2010; Vanderplank et al., 2014). 
Many tree species in the region, including Davidia involucrata, Tetracentron sinense, Cercidiphyllum japonicum and Tapiscia sinensis, were once widespread in the northern hemisphere but are now found only in East Asia (Manchester et al., 2009; Tang et al., 2014). Since 1956 national and provincial nature reserves have been established in China to prioritize the conservation of these vulnerable and threatened taxa (Wang \& Xie, 2004; Miller-Rushing et al., 2016; Zhang et al., 2016). Despite the large number of nature reserves and the significant investment in conservation, many programmes have failed to meet local ecological and socio-economic needs (Ma et al., 2009; Wang \& Buckley, 2010; Wang et al., 2012; Zheng \& Cao, 2015; Qian et al., 2016). The increasing rate of habitat loss caused by anthropogenic disturbance has led to poor regeneration of many threatened plant species (Zhang et al., 2015), highlighting a need for more effective in situ conservation practices. To inform policy makers and improve conservation programmes, nature reserves need to be studied and monitored, with the aim of developing more effective sustainable management frameworks, in China and elsewhere.

We investigated plant communities dominated by D. involucrata in a forest stand subject to intensive management activities in south-central China. Our study site is part of a national nature reserve established to protect first-grade nationally protected trees, including Cathaya argyrophylla and D. involucrata, and has a history of utilization and management of the bamboo Chimonobambusa utilis going back to the Song Dynasty (960-1279). Current management practices for bamboo in this area usually involve clearing away the underbrush to promote the growth of bamboo shoots and facilitate the spread of existing bamboo stands into adjacent vegetation. We examined plant community structure and the regeneration of $D$. involucrata both in this area and at two additional sites where $D$. involucrata communities are relatively well protected, to examine the influences of bamboo management on the effectiveness of the conservation of D. involucrata.

\section{Study area and species}

The study site lies in a forest stand on Mount Jinfo in Nanchuan District, Chongqing Municipality (Fig. 1). The area is part of the Mount Jinfo National Nature Reserve, which is a World Heritage site (Ma, 2016). Within the study site, $D$. involucrata and $C$. utilis have an overlapping elevational distribution ( $\mathrm{Li}, 2003$; $\mathrm{Li}$ et al., 2014) and the intensive management practices used by local people for C. utilis are having an impact on the regeneration of D. involucrata communities. We also selected two additional sites, where the plant communities are also dominated by D. involucrata but are undisturbed by human activities, as a control: one is on Mount Emei in Sichuan Province and the

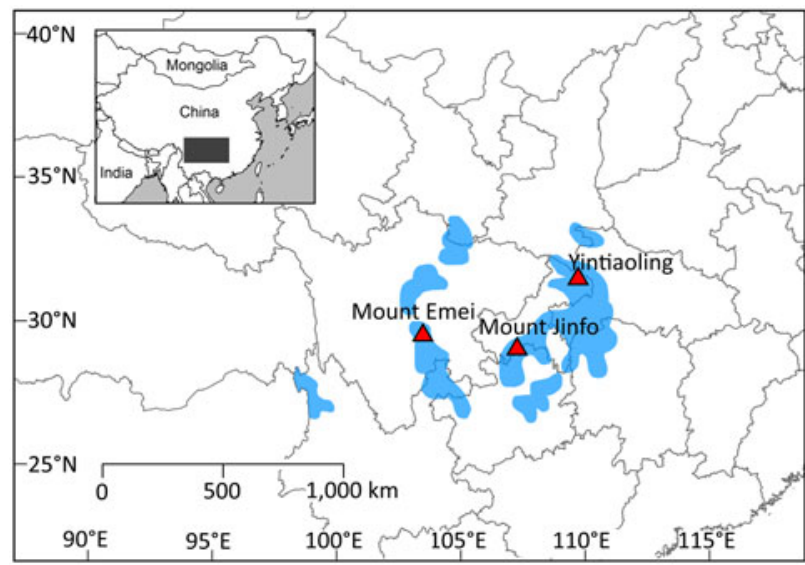

FIG. 1 The natural distribution of Davidia involucrata in China (shaded area), with the locations of the study sites: Mount Emei in Sichuan Province, and Mount Jinfo and Yintiaoling Nature Reserve in Chongqing Municipality.

other is in the Yintiaoling Nature Reserve in Chongqing Municipality (Fig. 1). The three sites are all located within the core distribution range of $D$. involucrata (Fig. 1). The two control sites are not in Mount Jinfo National Nature Reserve because it is difficult to find $D$. involucrata communities that are undisturbed by human activities within the Reserve. We chose the control sites on the basis that they are (1) at similar latitudes to Mount Jinfo National Nature Reserve $\left(\mathrm{c} .30^{\circ} \mathrm{N}\right)$ and thus their climatic conditions should not vary substantially from the study site, and (2) in the core distribution range of $D$. involucrata and comprise natural and representative $D$. involucrata communities, based on our field observations.

Davidia involucrata, also known as the dove tree, was first described by the French priest and naturalist Father Armand David on a trip to China in 1868, and then found again by the Scottish plant hunter Augustine Henry in the Yangtse Ichang gorges. Later, the plant collector Ernest Henry Wilson was employed to find Henry's tree, and he collected a large quantity of seeds and sent them back to England in 1901 (Gardener, 1972). Since 1904 the dove tree has been introduced to Europe and North America, and it is now a popular ornamental tree in parks and gardens. This relict species is endemic to south-central and south-western China, where it occurs in scattered stands on isolated mountain slopes, or in valleys. It was categorized as a first-grade nationally protected species in the Catalogue of the National Protected Key Wild Plants of 1999. Of the 29,716 known angiosperm species in China (Wang et al., 2015), only 33 have been categorized as first-grade protected species in the Catalogue of the National Protected Key Wild Plants of 1999, with 161 species categorized as second-grade protected species. Although D. involucrata has not yet been assessed for the IUCN Red List, it is reported that the natural 


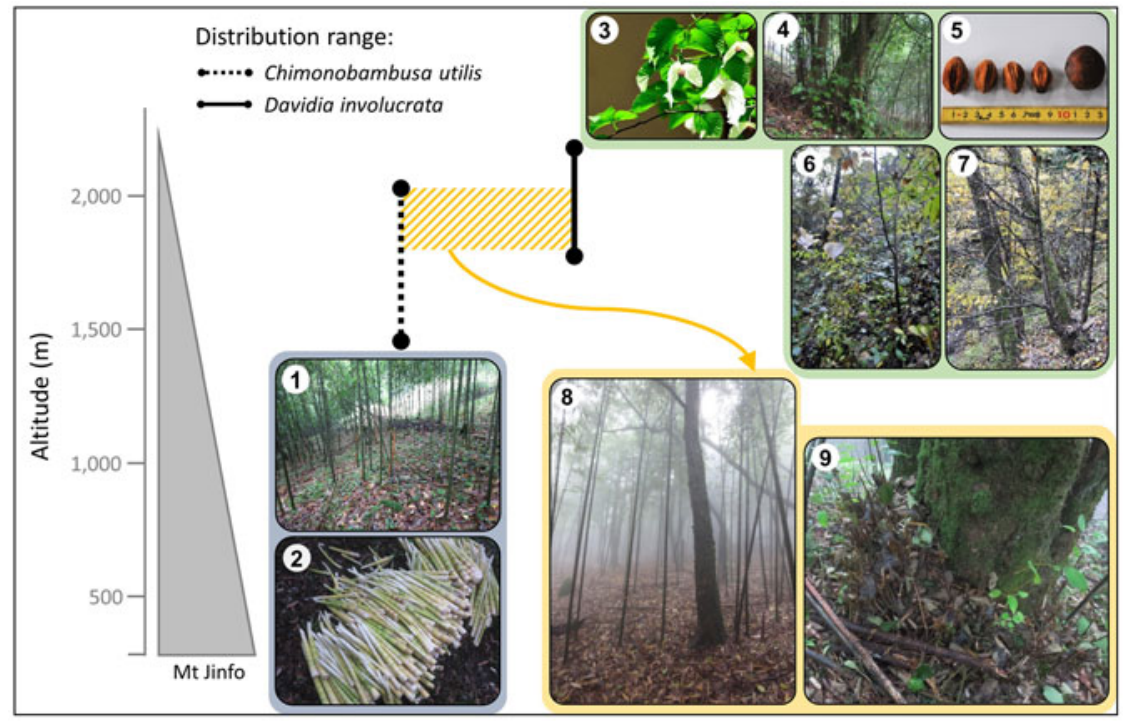

FIG. 2 The elevational distribution and habitats of the bamboo Chimonobambusa utilis and the dove tree D. involucrata on Mount Jinfo (Fig. 1). (1) Habitat of $C$. utilis, (2) harvested shoots of C. utilis, (35) D. involucrata at flowering, adult and fruit stages, respectively, (6-7) D. involucrata saplings, (8) understorey conditions in D. involucrata populations in managed forest stand, (9) damaged D. involucrata sprouts. Elevational distribution ranges of $C$. utilis and D. involucrata are based on Li et al. (2014) and Li (2003), respectively. The hatched area indicates the sites where the distribution of C. utilis and D. involucrata overlaps. Photographs 1, 2, 8 and 9 were taken at the study area on Mount Jinfo, and 6 and 7 were taken in the Yintiaoling Nature Reserve (Fig. 1).

TABLE 1 Habitat characteristics and woody floristic composition of the study site on Mount Jinfo, and the two control sites, on Mount Emei and in Yintiaoling Nature Reserve, China (Fig. 1).

\begin{tabular}{|c|c|c|c|}
\hline & Mount Jinfo & Mount Emei & $\begin{array}{l}\text { Yintiaoling } \\
\text { Nature Reserve }\end{array}$ \\
\hline Stand type & Managed & Natural & Natural \\
\hline Altitude (m) & $1,807-1,961$ & 1,620 & $1,347-1,486$ \\
\hline Sampling area $\left(\mathrm{m}^{2}\right)$ & 4,400 & 5,400 & 1,500 \\
\hline Mean inclination $\left({ }^{\circ}\right)$ & 35 & 30 & 40 \\
\hline Total no. of plant species & 30 & 42 & 26 \\
\hline \multicolumn{4}{|l|}{ Relative basal area $(\%)^{*}$} \\
\hline Davidia involucrata & 33.73 & 23.85 & 21.00 \\
\hline Tetracentron sinense & 14.47 & 4.42 & 18.60 \\
\hline Yulania sprengeri & 8.69 & & \\
\hline Acer oliverianum & 8.66 & 3.01 & \\
\hline Lithocarpus hancei & 4.14 & & \\
\hline Pterostyrax psilophyllus & 3.74 & & 19.45 \\
\hline Lithocarpus henryi & 3.70 & & \\
\hline Castanopsis platyacantha & 3.07 & 0.14 & \\
\hline Cerasus dielsiana & 2.43 & & \\
\hline Cladrastis delavayi & 2.35 & & \\
\hline Tapiscia sinensis & 2.07 & 2.99 & 0.72 \\
\hline Acer sterculiaceum subsp. franchetii & 1.87 & & \\
\hline Acer sinense & 1.64 & & \\
\hline Schima sinensis & 1.32 & & \\
\hline Illicium simonsii & 1.21 & & \\
\hline Padus buergeriana & 1.21 & & \\
\hline Cornus chinensis & 0.55 & 1.08 & \\
\hline Styrax hemsleyanus & & 17.44 & \\
\hline Cercidiphyllum japonicum & & 9.54 & 4.87 \\
\hline Pterocarya hupehensis & & 9.50 & \\
\hline Padus brachypoda & & 8.49 & \\
\hline Padus avium & & 6.17 & 8.87 \\
\hline Staphylea holocarpa & & 4.31 & \\
\hline Rhododendron argyrophyllum & & 1.90 & \\
\hline Aesculus chinensis var. wilsonii & & 1.18 & 2.27 \\
\hline Acer flabellatum & & 1.12 & \\
\hline Cornus controversa & & 0.13 & 2.55 \\
\hline Platycarya strobilacea & & & 6.19 \\
\hline
\end{tabular}


Table 1 (Cont.)

\begin{tabular}{|c|c|c|}
\hline & Mount Jinfo & $\begin{array}{l}\text { Yintiaoling } \\
\text { Nature Reserve }\end{array}$ \\
\hline Carpinus hupeana & & 3.02 \\
\hline Diospyros lotus & & 2.87 \\
\hline Kalopanax septemlobus & & 1.99 \\
\hline Toxicodendron succedaneum & & 1.71 \\
\hline Machilus ichangensis & & 1.56 \\
\hline Quercus engleriana & & 1.31 \\
\hline
\end{tabular}

${ }^{\star}$ Only species with relative basal area $>1 \%$ are listed. Values in bold indicate dominant species.
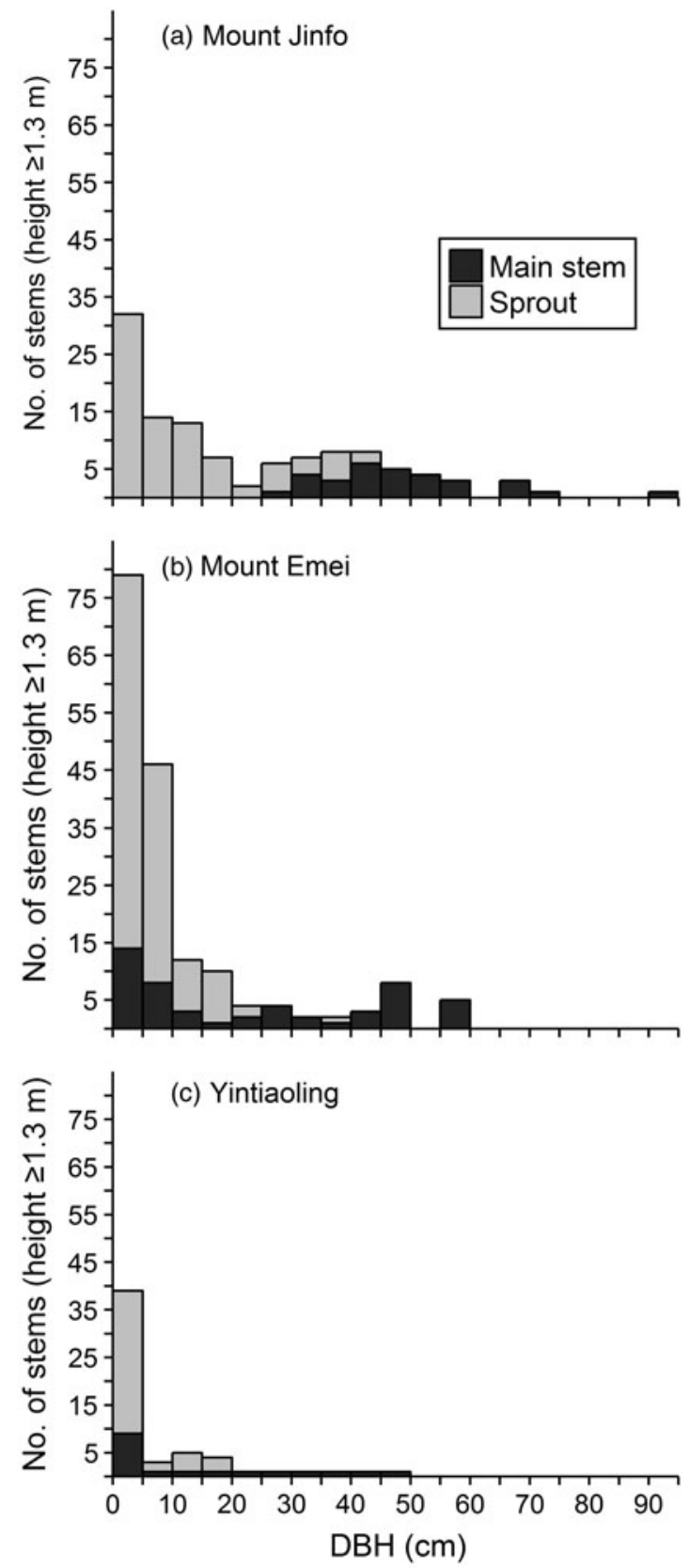

FIG. 3 Frequency distributions of the diameter at breast height (DBH) class for all D. involucrata individuals of $\geq 1.3 \mathrm{~m}$ height at the three study sites (Fig. 1). regeneration of this species is extremely poor $(\mathrm{Ma} \& \mathrm{Li}$, 2005; Zhang et al., 2008). In addition, there are no indications that the artificial cultivation of D. involucrata for landscaping in cities and botanical gardens has helped this species recover in the wild (Volis, 2016), and species distribution modelling has shown that only some areas of the current range of $D$. involucrata would be maintained under various climate change scenarios (Tang et al., 2017).

\section{Methods}

The characteristics of the plant communities on Mount Jinfo and in the Yintiaoling Nature Reserve, including size structure and floristic composition, were investigated following the patch sampling method (Ohsawa, 1991). We selected several vegetation patches of $100-900 \mathrm{~m}^{2}$, to include representative types of vegetation in the study sites. Within each vegetation patch the species were identified and the height and diameter at breast height $(\mathrm{DBH})$ of every individual (woody species $\geq 1.3 \mathrm{~m}$ tall) were recorded. On Mount Jinfo we often found evidence of newly emerging sprouts (usually $<1.3 \mathrm{~m}$ ) of $D$. involucrata having been cut and removed (Fig. 2); we marked the damaged trees and counted the number of sprouts cut vs those remaining per individual to quantify the level of damage. On Mount Emei, plant communities were investigated in a permanent plot of $5,400 \mathrm{~m}^{2}$, as described in Tang \& Ohsawa (2002). Investigations of the D. involucrata communities on Mount Jinfo and in Yintiaoling Nature Reserve were conducted in late summer in 2015, and data on D. involucrata communities on Mount Emei came from a permanent forest inventory reported in Tang \& Ohsawa (2002). We included data on D. involucrata on Mount Emei because, to our knowledge, this site is one of the few sites where the species is well protected and natural regeneration from seeds has been observed.

The dominant species in each plant community were determined based on the relative basal area of each species (Ohsawa, 1984). We used the age-diameter relationship reported in Tang \& Ohsawa (2002) to estimate the ages of main stems or sprouts of D. involucrata when necessary. 

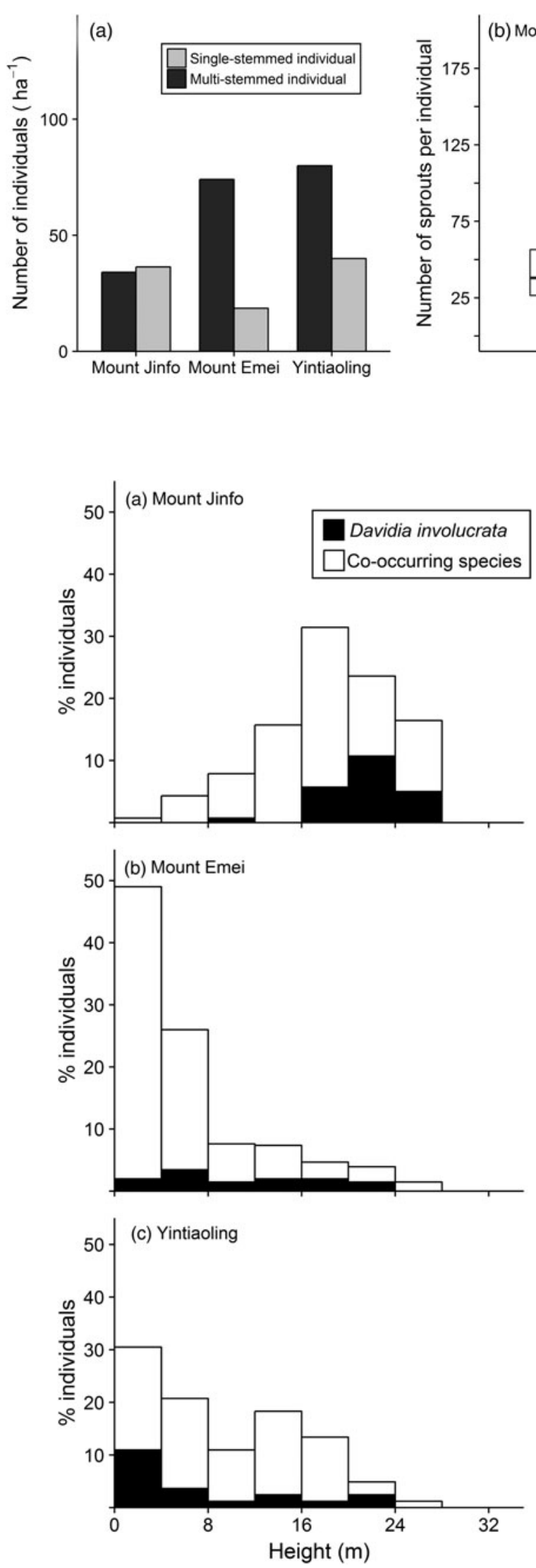

FIG. 5 Frequency distribution by height-class of $D$. involucrata communities at the three study sites (Fig. 1). In (a) the co-occurring species do not include C. utilis.

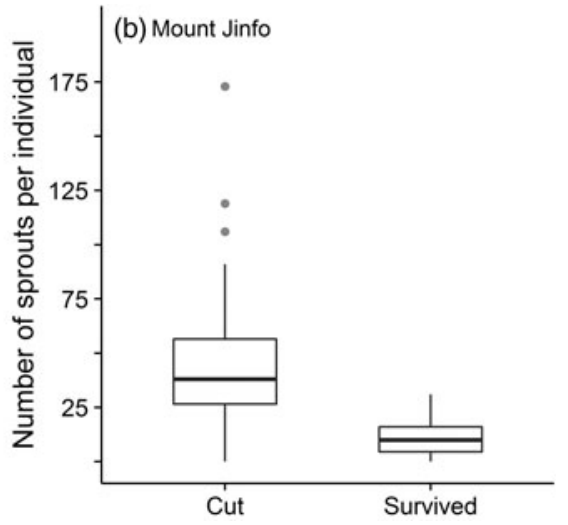

FIG. 4 (a) The numbers of single-stemmed and multi-stemmed $D$. involucrata individuals at each study site (Fig. 1), and (b) the mean numbers of cut and surviving sprouts (newly emerging sprouts at $<1.3 \mathrm{~m}$ height) of D. involucrata adults on Mount Jinfo. Whiskers indicate variability outside the upper and lower quartiles, and dots represent data outliers.

The mean number of stems of cut and surviving sprouts per adult individual of $D$. involucrata was compared using a paired $t$-test.

\section{Results}

The characteristics of the forest stands and plant communities in the three sites are summarized in Table 1. The plant communities were all co-dominated by $D$. involucrata and T. sinense. In addition, they share a number of relict components; for example, Pterostyrax psilophyllus, the codominant relict deciduous species in the Yintiaoling Nature Reserve, was also present in plant communities on Mount Jinfo. Tapiscia sinensis, although not a dominant species, was recorded in all plant communities in the three sites. At the two control sites, on Mount Emei and in the Yintiaoling Nature Reserve, the plant communities consisted of some additional relict trees, including C. japonicum and Aesculus chinensis var. wilsonii (Table 1).

On Mount Jinfo the main stems of D. involucrata were mostly of DBH 30-60 cm (Fig. 3a). On Mount Emei and in the Yintiaoling Nature Reserve, however, the DBH of $D$. involucrata has a continuous, inverse J-shaped distribution (Fig. 3b,c). Small stems of D. involucrata (DBH o-25 cm; height $\geq 1.3 \mathrm{~m}$ ) were absent from Mount Jinfo. Based on the generalized age-diameter relationship (Tang \& Ohsawa, 2002), the missing smaller stems would have been c. $0-50$ years old.

On Mount Jinfo the number of single-stemmed D. involucrata individuals was approximately equal to the number of multi-stemmed individuals. In contrast, on Mount Emei and in the Yintiaoling Nature Reserve the number of multi-stemmed individuals was higher than that of single-stemmed individuals (Fig. 4a). For newly emerging D. involucrata sprouts on Mount Jinfo, the number of sprouts cut per individual was significantly higher than the number of remaining sprouts $(t=-4.792, \mathrm{P}<0.001$; Fig. $4 \mathrm{~b})$.

The height-class distribution of the D. involucrata on Mount Jinfo had a unimodal pattern, with most 


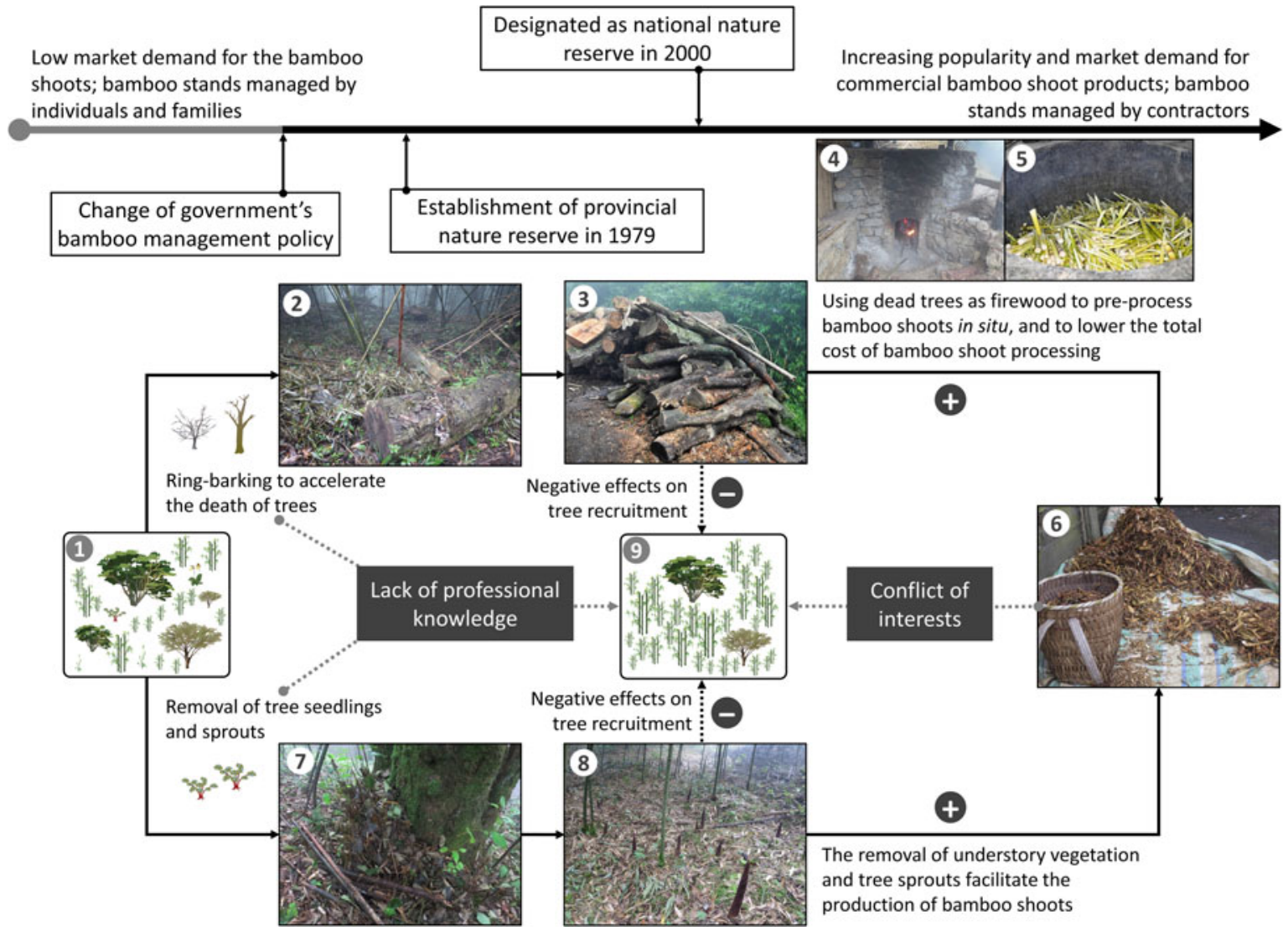

FIG. 6 The current management strategies for bamboo stands and D. involucrata communities on Mount Jinfo (Fig. 1). (1) Relatively balanced coexistence between bamboo and the D. involucrata communities prior to the change in government policy. (2-6) The use of certain measures to accelerate the death of trees other than $D$. involucrata, which are then used as firewood to boil and pre-process bamboo shoots in situ before they are dried out: (2) trunks of dead trees, (3) firewood made from dead trees, (4) a brick stove to boil and process the harvested bamboo shoots, (5) close-up of the brick stove, (6) processed and then dried bamboo shoots to be sold to the market. (7-8) To promote the growth and production of bamboo shoots and facilitate the spread of existing bamboo stands, understorey shrubs including young $D$. involucrata sprouts are intentionally cut and removed. (9) Current unbalanced coexistence between bamboo and the $D$. involucrata communities. The line at the top is a timeline of major events: c. 50 years ago a major, government-owned forest management centre was established on Mount Jinfo to promote the development and utilization of bamboo. Since then, bamboo management policy has changed significantly and the market for bamboo shoots has developed rapidly. In 1979 the Mount Jinfo Provincial Nature Reserve was established to protect species, including D. involucrata, in this area, and in 2000 this nature reserve was designated the Mount Jinfo National Nature Reserve.

individuals in the 16-28 $\mathrm{m}$ height-class (Fig. 5a). On Mount Emei and in the Yintiaoling Nature Reserve the height-class distributions were continuous, with the most abundant individuals (of both D. involucrata and cooccurring species) in the shrub and sub-canopy layer (1.3-8 m height-class; Fig. 5b,c).

\section{Discussion}

\section{Conflict between conservation and socio-economic development}

When establishing protected areas in China, recommendations were put forward that both ecological and socio-economic considerations be reviewed in planning management strategies (Xu et al., 2006; Ma et al., 2009; Wu, 2013). The missing D. involucrata main stems of $0-25 \mathrm{~cm}$ diameter at breast height, aged 0-50 years, on Mount Jinfo suggest that the exclusion of D. involucrata seedlings and new recruits in this area may have begun 4-5 decades ago. The size structure of $D$. involucrata mirrors the transformation of local economic development modes, together with a shift in the government's policy from individual-based management of bamboo stands to a contractor-based management plan (Fig. 6; pers. comm. with local workers and residents, August 2015). Official records show that in June 1965 a major, government-owned forest management centre was established on Mount Jinfo to promote the development and utilization of bamboo. Since then, the bamboo industry in the region has seen rapid development, resulting in 

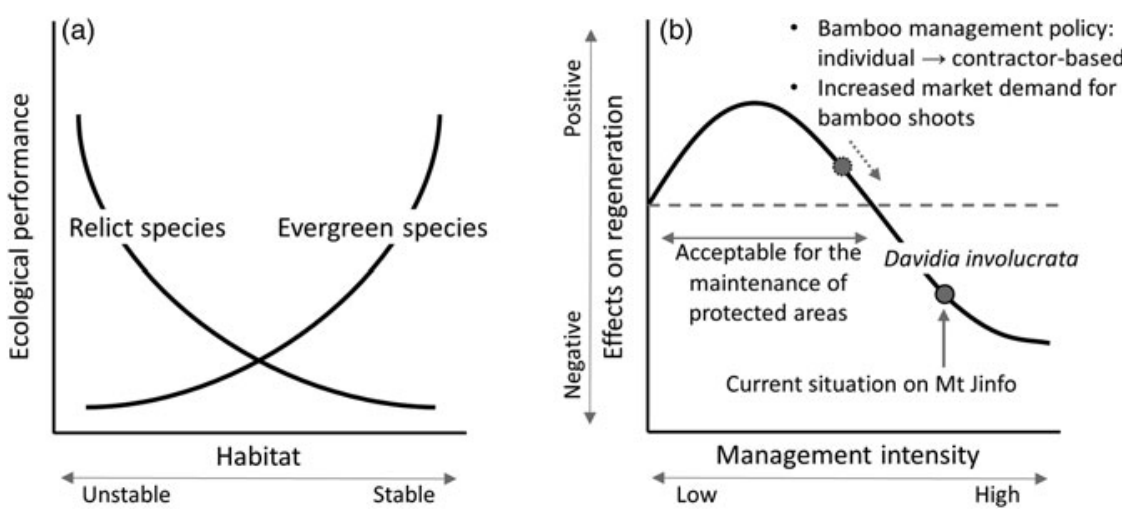

FIG. 7 (a) Regeneration strategies for relict trees and coexisting evergreen species in a typical relict plant community (revised from Tang \& Ohsawa, 2002). (b) Changes in the effect of bamboo management intensity on $D$. involucrata regeneration; the dotted circle shows the possible effects of management activity on the regeneration of $D$. involucrata at a medium level of management intensity, and the dashed arrow indicates the direction towards which the effects will change as the management intensity increases. The peak of the curve represents the optimum management intensity for the regeneration of $D$. involucrata. As management intensity increases beyond the point of intersection between the dashed line and the curve, the net effects of human activity on the regeneration of D. involucrata shift from positive to negative. increased intensity of bamboo management. In 1986 bamboo products (including bamboo timber and shoots) accounted for an annual revenue of c. USD 65,000. This increased to c. USD 120,000 in 1995, and USD 170,000 in 1998 (The Nanchuan Local Chronicle Editorial Committee, 2014). The harvesting and processing of bamboo shoots on Mount Jinfo has been scaled up to become a major business (the annual value of production in 2015 was c. USD 20 million), in parallel with the implementation of conservation action for D. involucrata (Nanchuan District People's Government, 2016). However, the need to develop a local bamboo shoot market and the existing intensified in situ management practices received little consideration during the establishment of the Mount Jinfo Provincial Nature Reserve in 1979 and the Mount Jinfo National Nature Reserve in 2000, possibly because a one-size-fits-all strategy was being used for establishing and maintaining national reserves in China (Xu et al., 2007, 2012). Bamboo shoot harvesting and processing have become major sources of income for many local residents, and the local government and sponsors in Nanchuan District wish to continue to develop, and invest in, the bamboo shoot market (Nanchuan District People's Government, 2016). Consequently, the ongoing development of the bamboo shoot industry conflicts with the goal of conserving threatened species, such as D. involucrata, in Mount Jinfo National Nature Reserve.

\section{The importance of sharing knowledge}

To manage forests in protected areas, various forms of knowledge must be integrated (Quesada et al., 2009; Raymond et al., 2010). In Mount Jinfo National Nature Reserve the current policy for conserving $D$. involucrata requires only that large trees be kept alive. Consequently, contractors and local workers focus on promoting the growth of bamboo shoots, the spread of existing bamboo stands, and lowering the cost of bamboo shoot processing. Small seedlings of $D$. involucrata are removed and the young sprouts are intentionally cut (Figs 4 \& 6). The management of other tree species includes ring-barking to accelerate their death. The dead trees are then used as firewood for boiling and pre-processing bamboo shoots in situ before they are dried (Fig. 6). Such measures are informal, and contribute significantly to the absence of small trees (D. involucrata and co-occurring species) in plant communities on Mount Jinfo (Figs 3 \& 5).

To integrate professional, ecological knowledge with current management strategies for the forests on Mount Jinfo, relevant parties must understand the life-history characteristics of the key plant species. The plant communities on Mount Jinfo comprise several dominant relict tree species, including D. involucrata and T. sinense (Table 1), and sprouting is a critical part of their life histories (Tang \& Ohsawa, 2002; Tang et al., 2013). In the absence of seedlings, sprouts are crucial for sustaining the recruitment and regeneration of the species in this forest. The gap in the $0-25 \mathrm{~cm}$ DBH class for D. involucrata on Mount Jinfo (Fig. 3a) confirms the significant lack of recruits from seedlings, and emphasizes the importance of sprouting for maintaining D. involucrata. As most of the newly emerging sprouts of $D$. involucrata are intentionally cut, this forest may be facing a future ecological crisis of structure and function.

In the unmanaged forest stands on Mount Emei the ability of relict deciduous trees such as D. involucrata to sprout and thus adapt to unstable habitats (e.g. scree slopes) 
enables them to avoid competition with coexisting evergreen trees, which generally establish themselves in stable environments such as on mountain ridges (Fig. 7a; Tang \& Ohsawa, 2002). Management activities such as selectively cutting neighbouring trees, when carried out at low intensity, can improve understorey light conditions and thus promote the regeneration of remaining $D$. involucrata individuals in the plant community. This may explain how, despite the long history of utilizing and managing bamboo on Mount Jinfo, D. involucrata persists. However, there is a threshold of intensity of bamboo management above which increasing management will have negative effects on the regeneration of $D$. involucrata because of an increase in interspecific competition (e.g. competition between $D$. involucrata and bamboo for light and belowground resources; Takahashi et al., 2003; Kisanuki et al., 2012) (Fig. 7b). Hence, in the long term, control of management intensity would benefit those involved in bamboo harvesting whilst minimizing the negative effects of these activities on the forest.

\section{Lessons learned for tree conservation}

Tang et al. (2011) investigated the structure and regeneration of natural populations of the conifer Metasequoia glyptostroboides in Hubei, south-central China and found a substantial portion of the seedlings and small trees were missing. As in the case of D. involucrata on Mount Jinfo, only adults of M. glyptostroboides are officially protected. Seeds have been collected for sale and seedlings have been moved to non-native habitats as landscape plants, leaving the understorey space as agricultural land for cultivating Coptis chinensis, a medicinal herb (Wang et al., 2005; Tang et al., 2011). Although the remaining adults of M. glyptostroboides and D. involucrata may survive in protected areas for several decades under current conservation practices, long-term persistence cannot be guaranteed without effective reproduction and recruitment. In contrast, populations of Ginkgo biloba, also endemic to China, have continuous size and age structures because local traditional beliefs have protected the seedlings, saplings and habitat of this speceis (Tang et al., 2012). Thus, management for maintenance of regeneration and recruitment is critical not only for the conservation of D. involucrata on Mount Jinfo but also for other threatened and highly valued species that may have similar life-history characteristics to $D$. involucrata.

\section{Acknowledgements}

We thank Qiuping Tan, Ting Li, Mei Pang and Jing Xiao for help with the field work, and Xiaoya Li of the Fauna \& Flora International China Programme for helpful discussions, and Martin Fisher, Cella Carr, Bo Chen and two anonymous reviewers for their constructive comments which contributed significantly to improving the quality of the manuscript. This study was supported by grants from the Key National Research and Development Plan Program (2016YFC050310203) to YY, the Special Funding for Postdoctoral Researcher of Chongqing (Xm2016083) and the China Postdoctoral Science Foundation (2016M592635) to SQ, the Fundamental Research Funds for the Central Universities (Project No. 106112016CDJXY210006) to LZ, and the National Natural Science Foundation of China (31500355) to KS.

\section{Author contributions}

YY and SQ designed the study. SQ analysed the data and wrote an initial draft of the article. YY, CQT, SQ, LZ and SY conducted the field work and collected the data. All authors contributed substantially to the development of the article.

\section{References}

Berkes, F., Colding, J. \& Folke, C. (20o8) Navigating SocialEcological Systems: Building Resilience for Complexity and Change. Cambridge University Press, Cambridge, UK.

Berkes, F., Folke, C. \& Colding, J. (200o) Linking Social and Ecological Systems: Management Practices and Social Mechanisms for Building Resilience. Cambridge University Press, Cambridge, UK.

Coggins, C.R. (2000) Wildlife conservation and bamboo management in China's southeast uplands. Geographical Review, 90, 83-111.

Daily, G. \& Ellison, K. (2012) The New Economy of Nature: The Quest to Make Conservation Profitable. Island Press, Washington, DC, USA.

Davis, A. \& Ruddle, K. (2010) Constructing confidence: rational skepticism and systematic enquiry in local ecological knowledge research. Ecological Applications, 20, 880-894.

DeFries, R., Hansen, A., Turner, B.L., Reid, R. \& Liu, J. (2007) Land use change around protected areas: management to balance human needs and ecological function. Ecological Applications, 17, 1031-1038.

Dudley, N. \& Stoulton, S. (2008) Defining Protected Areas: An International Conference in Almeria, Spain. IUCN, Gland, Switzerland.

Gardener, W.H. (1972) E. H. Wilson's first trip to China. Arnoldia, 32, 103-115.

Gardner, T.A., Barlow, J., Chazdon, R., Ewers, R.M., Harvey, C. A., Peres, C.A. \& Sodhi, N.S. (2009) Prospects for tropical forest biodiversity in a human-modified world. Ecology Letters, 12, 561-582.

Guan, L., Sun, G. \& CAO, S. (2011) China's bureaucracy hinders environmental recovery. Ambio, 40, 96-99.

Kisanuki, H., Kudo, T. \& Nakai, A. (2012) Removing aboveground vegetation facilitates survival but slows height growth of spruce saplings in a fenced, degraded sub-alpine forest in central Japan. Journal of Forest Research, 17, 110-115.

Li, Q.-Y., ZhANG, Z.-W., TAO, J.-P., LiU, J.-H. \& YonG, X.-H. (2014) Effect of elevation and canopy condition on morphological traits and leaf fluctuating asymmetry of a bamboo, Chimonobambusa utilis in Jinfo Mountain Nature Reserve, Southwest China. Sains Malaysiana, 43, 1119-1125. 
LI, Y.-X. (2003) Present state and perspectives of biological study on Davidia involucrata. Journal of China West Normal University (Natural Sciences), 24, 269-275. [In Chinese, with English abstract]

Liu, J., Dietz, T., Carpenter, S.R., Alberti, M., Folke, C., Moran, E. et al. (2007) Complexity of coupled human and natural systems. Science, 317, 1513-1516.

López-Pujol, J. \& Ren, M.-X. (2010) China: a hot spot of relict plant taxa. In Biodiversity Hotspots (eds V. Rescigno \& S. Maletta), pp. 123-137. Nova Science Publishers, New York, USA.

MA, K. (2016) Conservation of world natural heritage should be ensured and its contribution to local sustainable development promoted. Biodiversity Science, 24, 861-862. [In Chinese, with English abstract]

MA, Y. \& LI, J. (2005) Population structure of Davidia involucrata in Mt. Seven-sister Natural Reserve of central China's Hubei Province. Journal of Beijing Forestry University, 27, 12-16. [In Chinese, with English abstract]

MA, Z., Li, B., Li, W., Han, N., Chen, J. \& Watkinson, A.R. (2009) Conflicts between biodiversity conservation and development in a biosphere reserve. Journal of Applied Ecology, 46, 527-535.

Manchester, S.R., Chen, Z.-D., Lu, A.-M. \& Uemura, K. (2009) Eastern Asian endemic seed plant genera and their paleogeographic history throughout the Northern Hemisphere. Journal of Systematics and Evolution, 47, 1-42.

McNeely, J.A. (1990) The future of national parks. Environment: Science and Policy for Sustainable Development, 32, 16-41.

Miller-Rushing, A.J., Primack, R.B., MA, K. \& Zhou, Z.-Q. (2016) A Chinese approach to protected areas: a case study comparison with the United States. Biological Conservation, http://dx.doi.org/10.1016/j.biocon.2016.05.022.

Myers, N., Mittermeier, R.A., Mittermeier, C.G., Da Fonseca, G.A.B. \& KenT, J. (2000) Biodiversity hotspots for conservation priorities. Nature, 403, 853-858.

Nanchuan District People's Government (2016) Industrial Development of the Bamboo Shoot in Nanchuan District. Nanchuan District People's Government, Nanchuan, Chongqing. Http://www.cqnc.gov.cn/Content/2016-02/19/content_245189.htm [accessed 20 December 2016]. [In Chinese]

Newmark, W.D., Leonard, N.L., S Ariko, H.I. \& Gamassa, D.-G.M. (1993) Conservation attitudes of local people living adjacent to five protected areas in Tanzania. Biological Conservation, 63, 177-183.

Ohsawa, M. (1984) Differentiation of vegetation zones and species strategies in the subalpine region of Mt. Fuji. Vegetatio, 57, 15-52.

Ohsawa, M. (1991) Structural comparison of tropical montane rain forests along latitudinal and altitudinal gradients in south and east Asia. Vegetatio, 97, 1-10.

Qian, S., YAnG, Y., TANG, C.Q., Momohara, A., YI, S. \& Ohsawa, M. (2016) Effective conservation measures are needed for wild Cathaya argyrophylla populations in China: insights from the population structure and regeneration characteristics. Forest Ecology and Management, 361, 358-367.

Quesada, M., Sanchez-Azofeifa, G.A., Alvarez-Añorve, M., Stoner, K.E., Avila-Cabadilla, L., Calvo-Alvarado, J. et al. (2009) Succession and management of tropical dry forests in the Americas: review and new perspectives. Forest Ecology and Management, 258, 1014-1024.

Raymond, C.M., Fazey, I., Reed, M.S., Stringer, L.C., Robinson, G.M. \& Evely, A.C. (2010) Integrating local and scientific knowledge for environmental management. Journal of Environmental Management, 91, 1766-1777.

Takahashi, K., Uemura, S., Suzuki, J.-I. \& Hara, T. (2003) Effects of understory dwarf bamboo on soil water and the growth of overstory trees in a dense secondary Betula ermanii forest, northern Japan. Ecological Research, 18, 767-774.
Tang, C.Q., Dong, Y.-F., Herrando-Moraira, S., Matsui, T., Ohashi, H., He, L.-Y. et al. (2017) Potential effects of climate change on geographic distribution of the Tertiary relict tree species Davidia involucrata in China. Scientific Reports, 7 , http://dx.doi.org/10.1038/srep43822.

TANG, C.Q. \& OHSAWA, M. (2002) Tertiary relic deciduous forests on a humid subtropical mountain, Mt. Emei, Sichuan, China. Folia Geobotanica, 37, 93-106.

TAng, C.Q., Peng, M.-C., He, L.-Y., Ohsawa, M., Wang, C.-Y., Xie, T.-H. et al. (2013) Population persistence of a Tertiary relict tree Tetracentron sinense on the Ailao Mountains, Yunnan, China. Journal of Plant Research, 126, 651-659.

TAng, C.Q., Werger, M.J.A., OhSAwa, M. \& YAng, Y. (2014) Habitats of Tertiary relict trees in China. In Endemism in Vascular Plants (ed. C. Hobohm), pp. 311-321. Springer, Dordrecht, The Netherlands.

Tang, C.Q., Yang, Y., Ohsawa, M., Momohara, A., Hara, M., Cheng, S. \& FAn, S. (2011) Population structure of relict Metasequoia glyptostroboides and its habitat fragmentation and degradation in South-Central China. Biological Conservation, 144, 279-289.

TAnG, C.Q., Yang, Y., Ohsawa, M., Yi, S.-R., Momohara, A., Su, W.-H. et al. (2012) Evidence for the persistence of wild Ginkgo biloba (Ginkgoaceae) populations in the Dalou Mountains, southwestern China. American Journal of Botany, 99, 1408-1414.

The Nanchuan Local Chronicle Editorial Committee (2014) Nanchuan District Annuals (1986-2006). China Local Records Publishing, Chongqing, China. [In Chinese]

Vanderplank, S., Moreira-Muñoz, A., Нobohm, C., Pils, G., Noroozi, J., Clark, V.R. et al. (2014) Endemism in mainland regions-case studies. In Endemism in Vascular Plants (ed. C. Hobohm), pp. 205-308. Springer, Dordrecht, The Netherlands.

Volis, S. (2016) How to conserve threatened Chinese plant species with extremely small populations? Plant Diversity, 38, 45-52.

WANG, C.-H. \& BUCKLEY, R. (2010) Shengtai anquan: managing tourism and environment in China's forest parks. Ambio, 39, 451-453.

WAnG, G., InNes, J.L., Wu, S.W., KrZyZAnowski, J., Yin, Y., Dai, S. et al. (2012) National park development in China: conservation or commercialization? Ambio, 41, 247-261.

WANG, L., JiA, Y., ZhanG, X. \& QIN, H. (2015) Overview of higher plant diversity in China. Biodiversity Science, 23, 217-224. [In Chinese, with English abstract]

WAng, S. \& XIE, Y. (2004) China Species Red List. Volume I. Red List. Higher Education Press, Beijing, China.

WAnG, X., MA, L., Guo, B., FAn, S. \& TAn, J. (2005) Analysis on the changes of the original Metasequoia glyptostroboides population and its environment in Lichuan, Hubei from 1948 to 2003. Acta Ecologica Sinica, 25, 972-977. [In Chinese, with English abstract]

Wu, J. (2013) Landscape sustainability science: ecosystem services and human well-being in changing landscapes. Landscape Ecology, 28, 999-1023.

XU, J., Chen, L., Lu, Y. \& FU, B. (2006) Local people's perceptions as decision support for protected area management in Wolong Biosphere Reserve, China. Journal of Environmental Management, $78,362-372$.

Xu, J., Zhang, Z., Liu, W. \& McGowan, P.J.K. (2012) A review and assessment of nature reserve policy in China: advances, challenges and opportunities. Oryx, 46, 554-562.

Xu, J.-Y., Chen, L.-D., Lu, Y.-H. \& Fu, B.-J. (2007) Sustainability evaluation of the Grain for Green Project: from local people's responses to ecological effectiveness in Wolong Nature Reserve. Environmental Management, 40, 113-122.

Zhang, J., Li, Z., Fritsch, P.W., Tian, H., YANG, A. \& YaO, X. (2015) Phylogeography and genetic structure of a Tertiary relict tree 
species, Tapiscia sinensis (Tapisciaceae): implications for conservation. Annals of Botany, 116, 727-737.

Zhang, L., Luo, Z., Mallon, D., Li, C. \& JiAng, Z. (2016) Biodiversity conservation status in China's growing protected areas. Biological Conservation, http://dx.doi.org/10.1016/j.biocon.2016.05. 005.

Zhang, W., CaO, G.-X., LiU, G.-H. \& LiU, X. (2008) Population structure and distribution pattern of Davidia involucrata at Labahe Nature Reserve of Sichuan Province. Journal of Zhejiang Forestry College, 25, 451-457. [In Chinese, with English abstract]

ZhenG, H. \& CAO, S. (2015) Threats to China's biodiversity by contradictions policy. Ambio, 44, 23-33.

\section{Biographical sketches}

Shenhua Qian's research focuses on population dynamics and the conservation of biodiversity. CINDY Q. TANG's research interests include the conservation of relict species and the origins and development of subtropical forests. SIRONG YI's research interests include forest conservation and management. LIANG ZHAO is interested in the relationship between biodiversity and ecosystem functioning. KUnG Song's research focuses on the processes and mechanisms structuring the plant communities in subtropical forests. YONGCHUAN YANG's research interests incorporate many aspects of the conservation of relict species. He also has a special interest in biodiversity patterns in urban ecosystems. 